\title{
Controlled Growth of Palladium Nanoparticles on Graphene Nanoplatelets via Scalable Atmospheric Pressure Atomic Layer Deposition
}

\author{
Hao Van Bui ${ }^{1, \dagger, *}$, Fabio Grillo ${ }^{1, \dagger}$, Ryan Helmer ${ }^{1}$, Aristeidis Goulas ${ }^{2}$, and J. Ruud van Ommen ${ }^{1}$ \\ ${ }^{1}$ Department of Chemical Engineering, Delft University of Technology, 2628 BL, Delft, The \\ Netherlands
}

${ }^{2}$ Delft IMP B.V., 2628 BL, Delft, The Netherlands

${ }^{\dagger}$ Contributed equally to this work

*Corresponding author: V.H.Bui@tudelft.nl;

Telephone: +31 (0) 152782635

\section{Supporting Information}

Growth of Pd on graphene

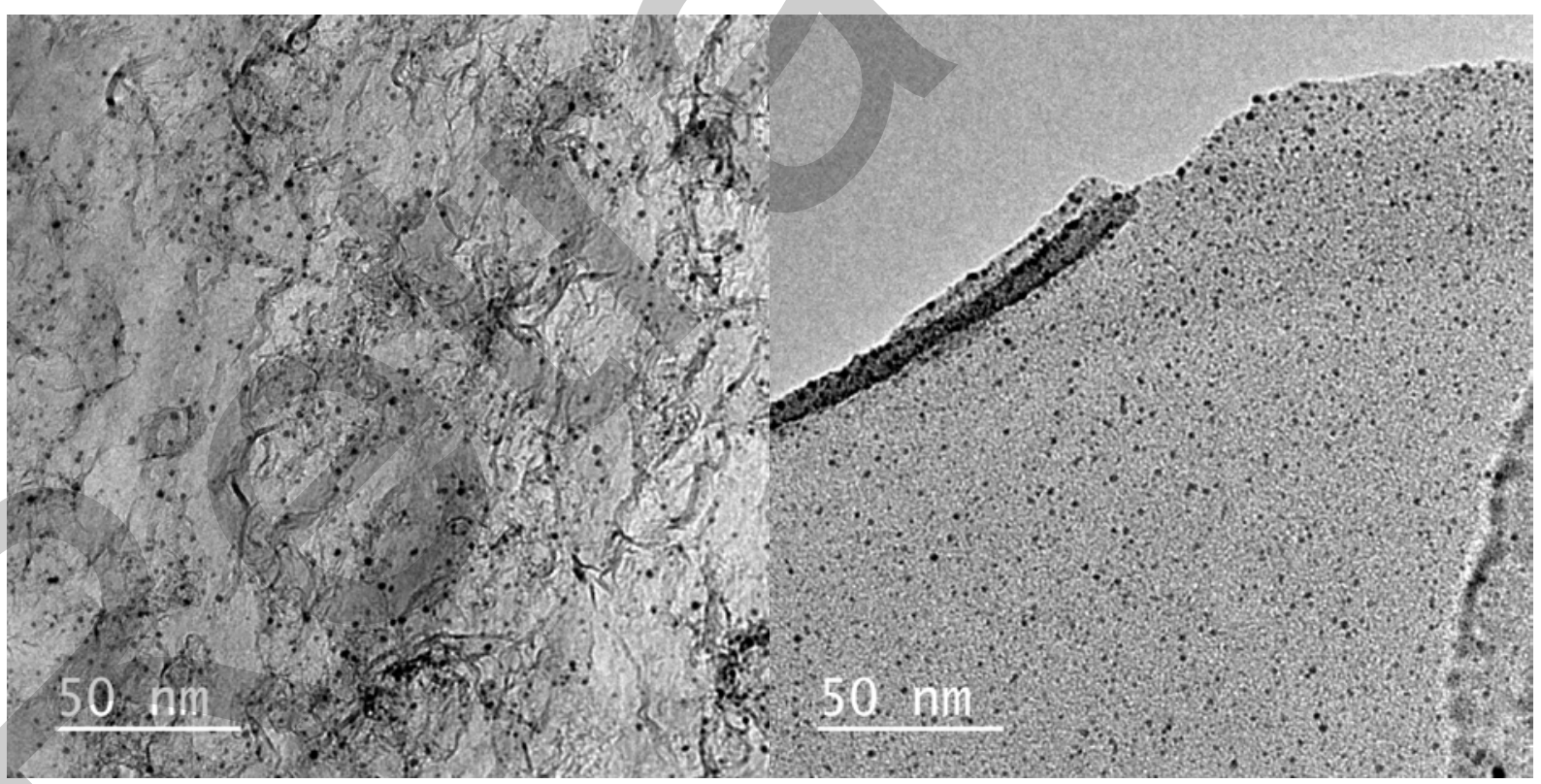

Figure S1. TEM images of Pd nanoparticles deposited on graphene basal planes (left) and edges (right) at $220^{\circ} \mathrm{C}$ for $3 \mathrm{ALD}$ cycles. The graphene was treated in ozone at $150{ }^{\circ} \mathrm{C}$ for 60 minutes prior to the Pd ALD. 


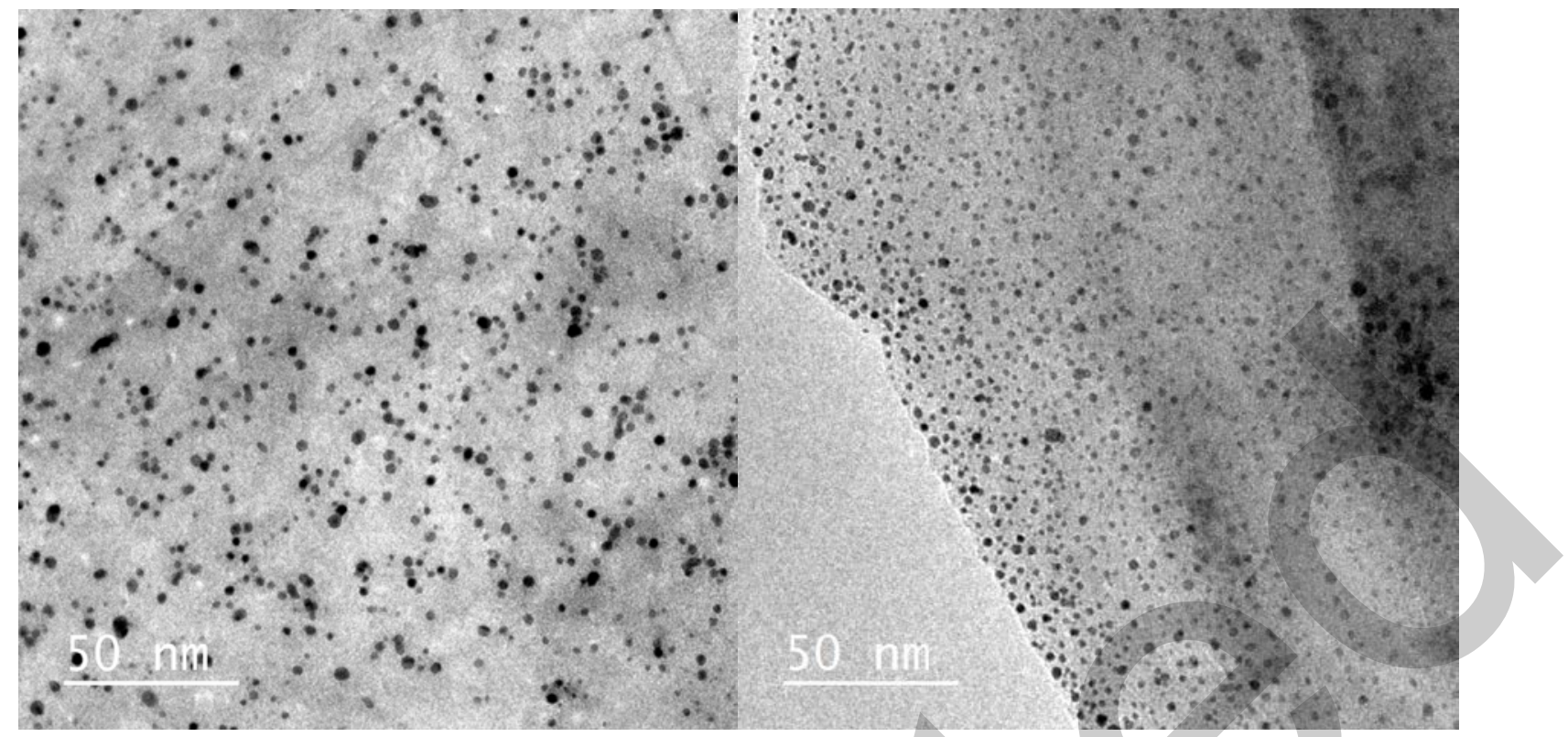

Figure S2. TEM images of Pd nanoparticles deposited on graphene basal planes (left) and edges (right) at $220^{\circ} \mathrm{C}$ for 6 cycles. The graphene was treated in ozone at $150{ }^{\circ} \mathrm{C}$ for 60 minutes prior to the Pd ALD.

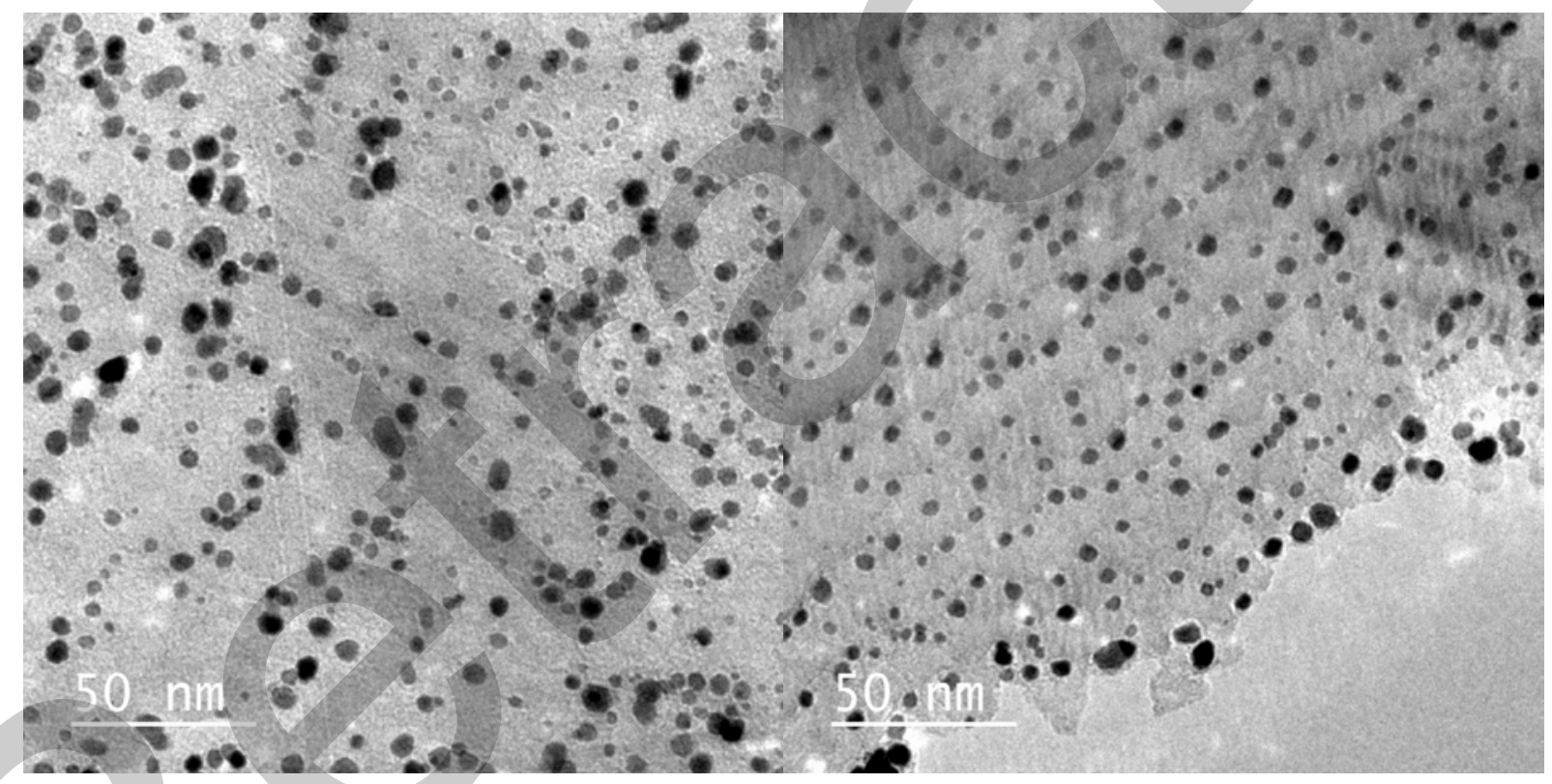

Figure S3. TEM images of Pd nanoparticles deposited on graphene basal planes (left) and edges (right) at $220^{\circ} \mathrm{C}$ for $12 \mathrm{ALD}$ cycles. The graphene was treated in ozone at $150{ }^{\circ} \mathrm{C}$ for 60 minutes prior to the Pd ALD. 


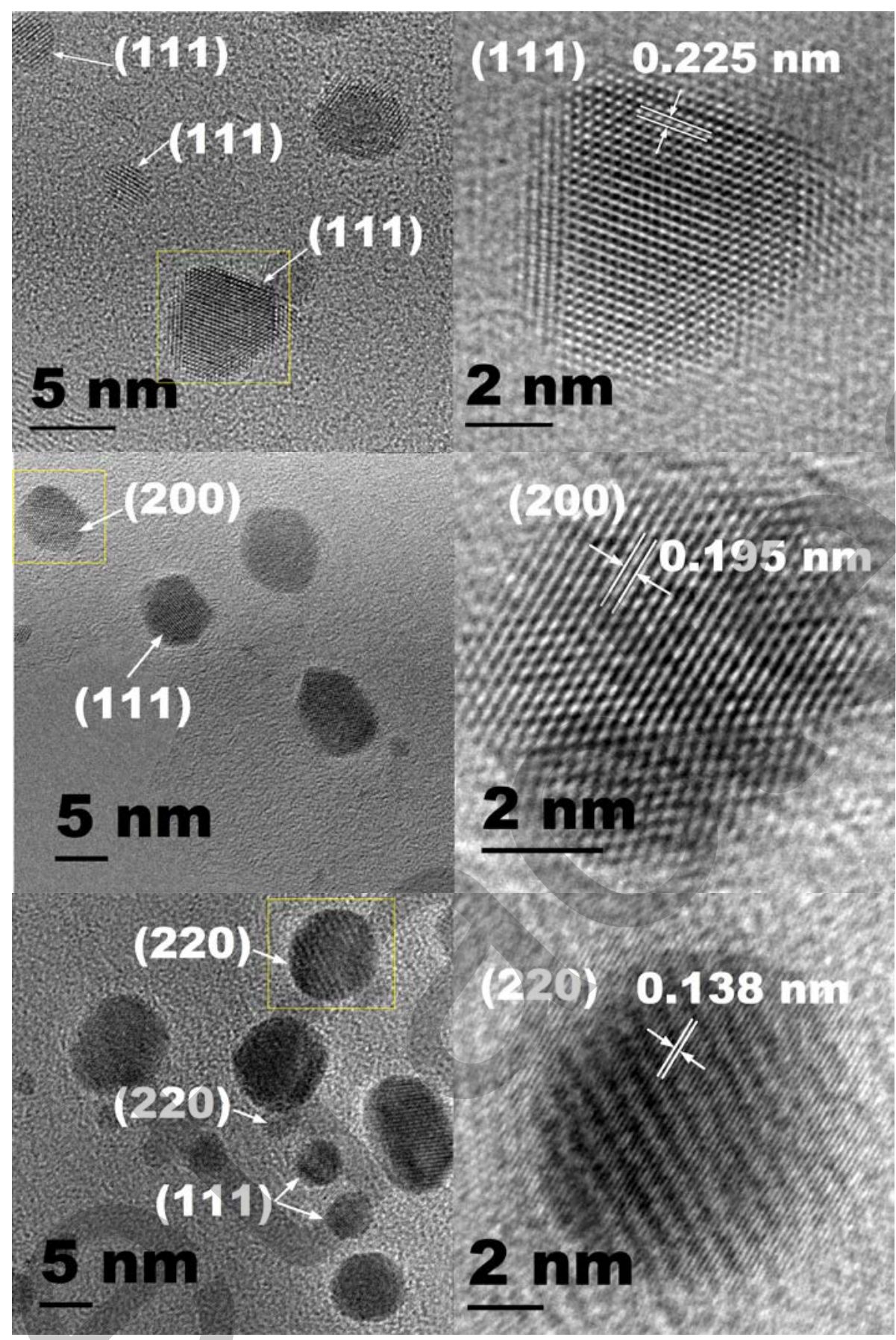

Figure S4. HRTEM of Pd NPs for 12 ALD cycles showing three crystallographic facets (111), (200) and (222) of the FCC crystalline structure of platinum. The images on the right side show the particles marked by the squares in the corresponding images on the left sides. We observed the dominance of the (111) orientations, which is in good agreement with the XRD pattern shown in Figure 4 of the manuscript. 


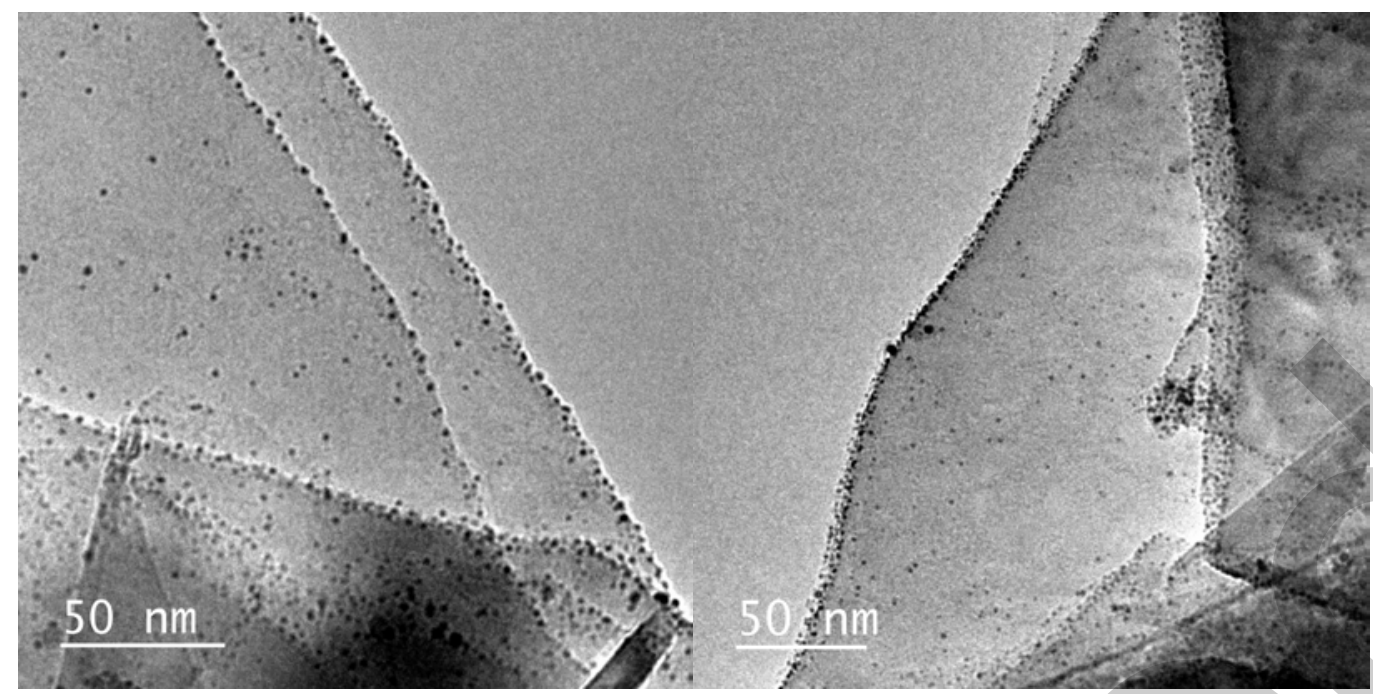

Figure S5. TEM images of Pd nanoparticles deposited on graphene at $220{ }^{\circ} \mathrm{C}$ after 12 cycles measured at different locations. The graphene was treated in ozone at $150{ }^{\circ} \mathrm{C}$ for 30 minutes prior to the Pd ALD.

\section{Raman spectroscopy of Pd/graphene}
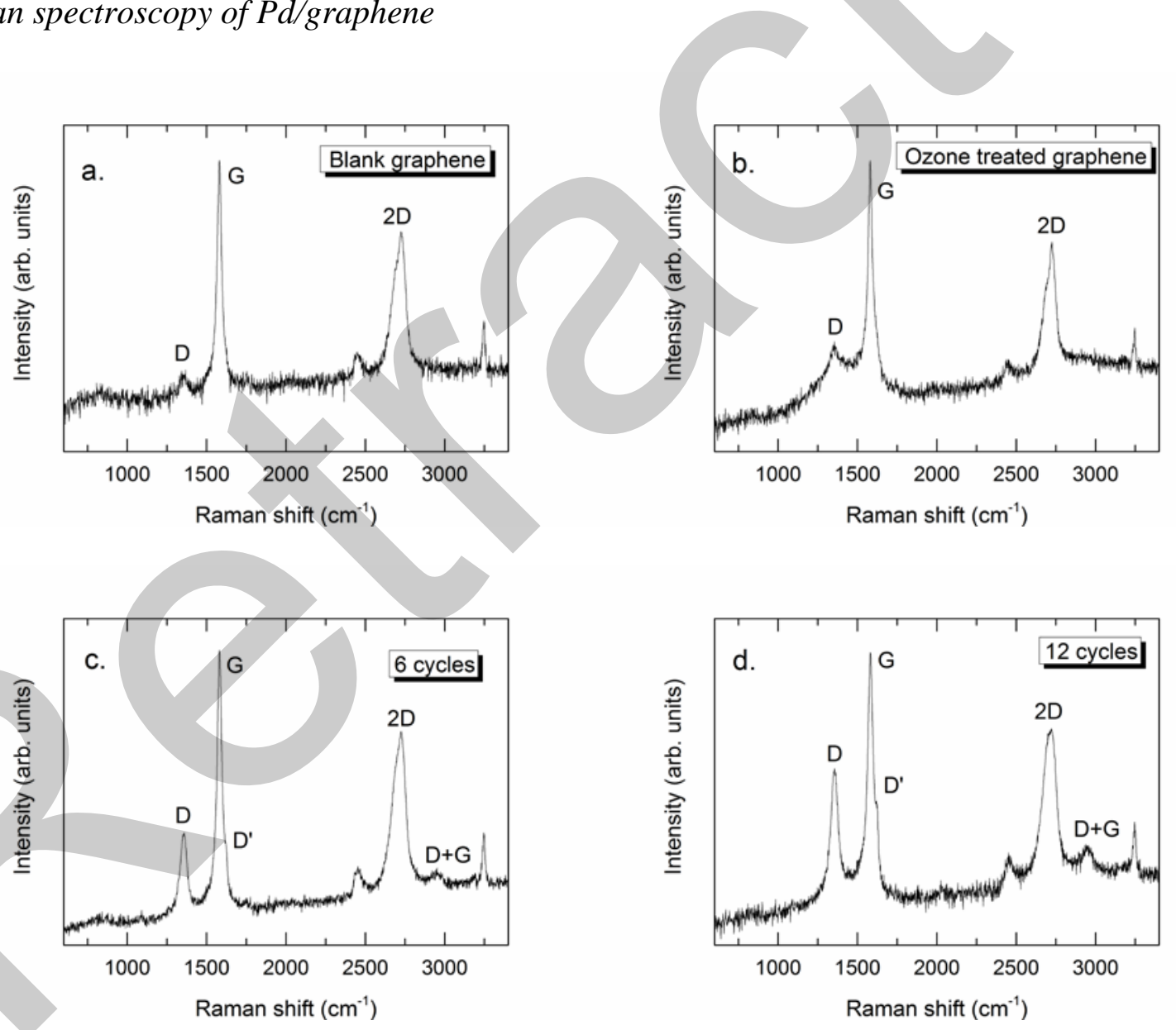

Figure S6. Raman spectra of (a) untreated graphene, (b) $\mathrm{O}_{3}$-treated graphene and Pd/graphene for (c) 6 and (d) 12 ALD cycles. The Y-axis (Intensity) is plotted in $\log _{10}$ scale. 


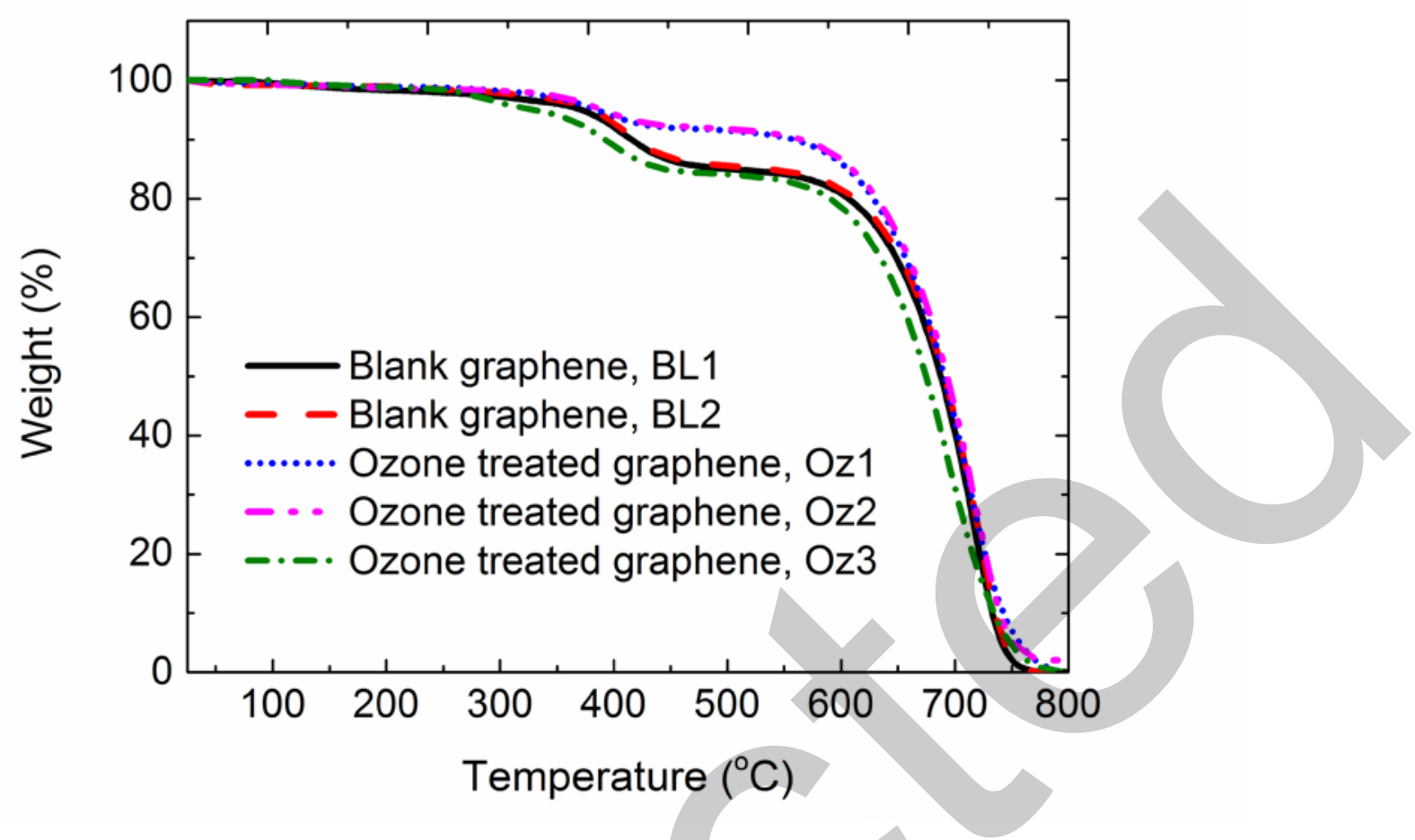

Figure S7. TGA curves of untreated graphene samples (BL1 and BL2), and the ozone treated graphene for $60 \mathrm{~min}$ at $150{ }^{\circ} \mathrm{C}(\mathrm{Oz} 1, \mathrm{Oz} 2$ and $\mathrm{Oz} 3)$. The TGA of sample Oz1 and Oz2 was measured 3 days and 5 days after the ozone treatment had been performed, respectively. The TGA of sample Oz3 was measured 2 months after the ozone treatment had been performed. The results indicate that the functional groups created by ozone treatment remained on the graphene surface for a few days in atmospheric environment. However, the initial surface was recovered after a long period.

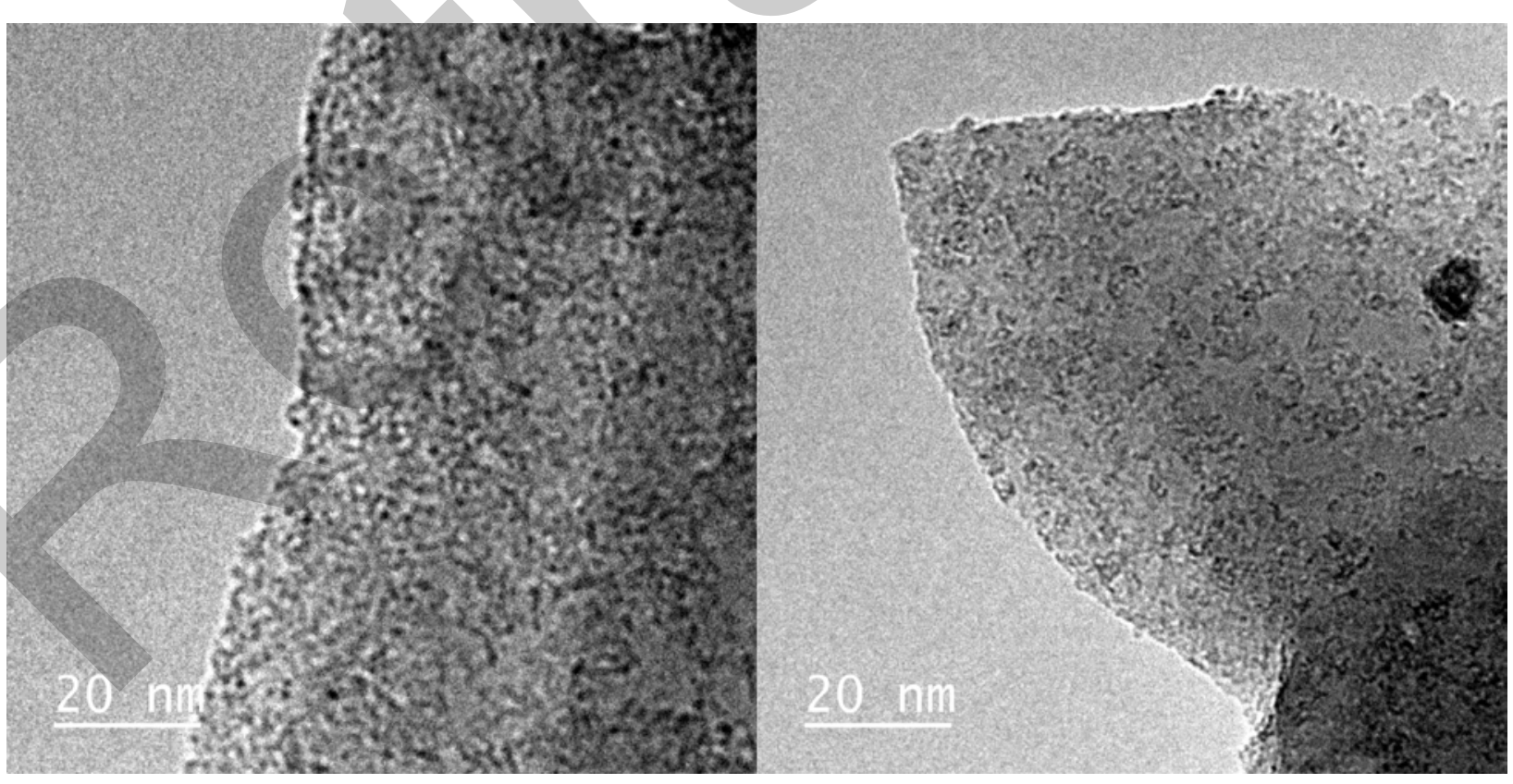

Figure S8. TEM images of Pd nanoparticles deposited on graphene at $220^{\circ} \mathrm{C}$ after 1 cycle measured at different locations. The graphene was treated in ozone at $150{ }^{\circ} \mathrm{C}$ for 60 minutes prior to the Pd ALD. 